\title{
DIRECT STRUT-AND-TIE MODEL FOR REINFORCED CONCRETE BRIDGE PIER CAP
}

HEMANT KUMAR VINAYAK - Assistant professor, PhD, ${ }^{1}$ Department of Civil Engineering, National Institute of Technology, Hamirpur-177005, H.P., India.

SIVAA SENTHIL N.A.K - TATA consultancy Engineer, Chennai, Email: senthil.sabap@gmail.com

PRADEEP KUMAR T V - Tandon Consultants Pvt Ltd, New Delhi-110014, India.

\begin{abstract}
A simple and direct Strut-and-Tie Model (STM) is proposed here to predict the ultimate shear strength of the reinforced concrete bridge pier cap for shear span to depth ratio of 0.4 to 2.4. The model is based on the Kupfer-Gerstle Biaxial Compression-Tension failure criterion which includes the concrete softening effect produced by the presence of transverse tensile stress. The earlier models consider the stress distribution factor for the varied stress distribution across the section by assuming it as linear function which is derived by satisfying equilibrium conditions. In this study the principal stresses have been evaluated by satisfying the compatibility condition at the time of impending failure which has been accounted for the effective area of concrete resisting tension. Also the softening effect has been included by using the formula for tensile strength of cracked concrete proposed by Belarbi and Hsu. The proposed model has been validated with 43 experimental results by author and from literature which confirm the coherency and conservativeness of the predicted results. The parametric study on ultimate shear strength is done so as to infer the relation between various abstract quantities such as compressive strain, shear capacity, span depth ratio and other material properties and get a deeper insight into the behavior of the Pier cap. Thus this paper tries to extend the practical application of Strut-and-Tie Model for reinforced concrete bridge pier cap in understanding the actual behavior of the structure on various dimensional and material parameters.
\end{abstract}

Keywords: Disturbed regions, Strut-and-Tie Model, Pier Cap, Ultimate Shear Strength

\section{Introduction}

Strut-and-Tie Model proves to be a valuable rational tool for analyzing disturbed regions where Bernoulli-Euler's theory of plane sections becomes invalid [1], [2]. As for the shear design of reinforced bridge pier cap there exist no codal provisions available except the recommendation for using STM [3]. The most common practice of STM involves assuming various stress limits so as to include all possible stress condition that could take part in STM components i.e. nodal zones and struts. But the reason behind such modeling uncertainty in predicting failure load can be attributed to the empirical nature in defining such stress limits [4]. There exists number of stress criteria postulated and tested by numerous researchers[5], [6], [7], [8], [9]. Unlike the direct STM proposed by [9], where the stress distribution factor $\mathrm{k}$ is adopted to represent the actual stress values along the section by satisfying force equilibrium condition and subsequently the moment equilibrium by [10], this study has considered the effective depth of concrete resisting tension by satisfying the strain compatibility condition at the state of failure. Further the formula for shear strength is based on Kupfer-Gerstle biaxial tension-compression failure criterion because the failure is assumed to initiate from Compression-Compression-Tension (CCT) node at the point of load. By considering such interactive failure criterion we take into account the concrete softening effect due to the presence of transverse tensile strain. The contribution of concrete under tension is calculated from [11] equation for tensile strength of cracked concrete.

The proposed STM has been evaluated with 43 test results by the author and from the previous works. It has been observed that the proposed model based on strain compatibility where the 
effective depth of concrete resisting tension is derived on assumed maximum compressive strain whose influence on shear strength is less than 5\% as compared to the model proposed by Tan model and Wang model, where stress distribution factor $\mathrm{k}$ has about $20 \%$ of mean result on the ultimate shear strength. This suggests us to use any relevant strain value mentioned by the respective codes withoutaffecting the ultimate shear strength results significantly. The results seem to be more accurate, consistent and conservative which can be highly reliable while designing the structure. Further the parametric studies indicate the applicability range of proposed STM and sensitivity of shear strength to shear span to depth ratio, compressive strength of concrete and the influence of maximum compressive strain of concrete on the ultimate shear strength.

\section{Modeling T-headed pier cap}

A strut and tie model for T-Headed pier cap is proposed in Fig.1. From the equilibrium of the forces of the system, we get

$$
\begin{gathered}
F_{c}=\frac{V_{n}}{\sin \theta_{s}} \\
T=\frac{V_{n}}{\tan \theta_{s}}
\end{gathered}
$$

Where:

$F_{C}=$ Compressive force in the diagonal strut;

$T=$ Tensile force in the horizontal tie;

$V_{n}=$ Nominal shear strength;

$\theta_{s}=$ Inclined angle of diagonal strut.

$K=$ Stress distribution factor

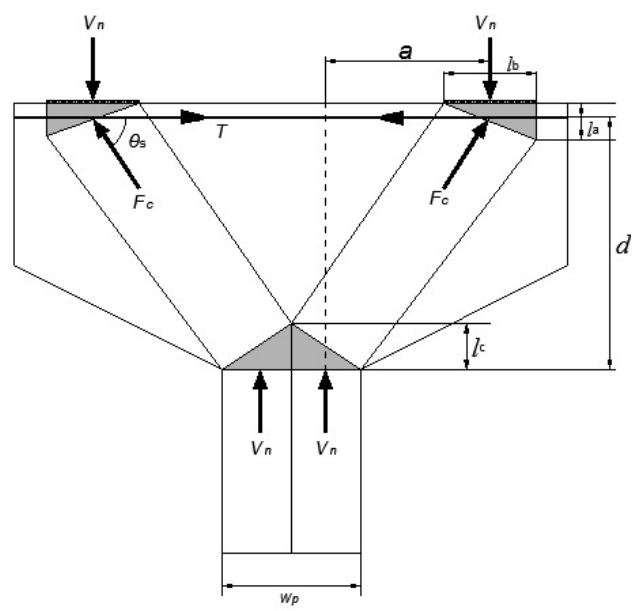

Fig.1 Proposed Strut-and-Tie Model for Pier Cap

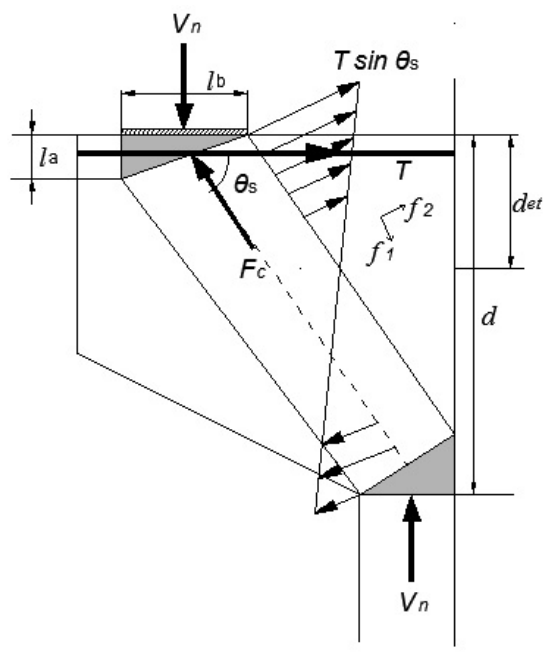

Fig.2 Determination of Principal Stresses at Nodal Zones Cap

Here we consider Compression-Compression-Tension (CCT) nodal zone at the pier bearing because of the presence of relatively higher in-plane stresses. In finding the principal compressive stress the effect due to the main tie reinforcement $T \cos \theta_{s}$. For smaller $a / d$ ratio of the pier cap $\cos \theta_{s}$ will approach zero and hence it can be ignored because of its insignificant magnitude but for the case of higher $a / d$ ratio this quantity becomes more significant and hence neglecting such quantity would result in underestimation of shear strength of the system. 
The principal compressive stress $f_{2}$ in the direction of the diagonal strut is given by,

$$
f_{2}=\frac{F_{C}-T \cos \theta_{s}}{A_{s t r}}
$$

Where, $A_{s t r}=$ the cross-sectional area of diagonal strut at the top nodal zone. The term $A_{s t r}$ is defined as,

$$
A_{s t r}=b_{w}\left(l_{a} \cos \theta_{s}+l_{b} \sin \theta_{s}\right)
$$

Here $b_{w}$ is the pier width, $l_{b}$ is the length of the bearing upon which the load is acting and $l_{a}$ is the depth of the top nodal zone which should not be less than the value found from the concept of hydrostatic nodal zone where the nodal zones were assumed to have equal stress on all in-plane sides. Because Mohr's circle for the in-plane stresses acting on such nodal zones plots as a point, this class of nodes was referred as hydrostatic nodal zones. Minimum value of $l_{a}$ is given by

$$
l_{a}=\frac{f_{y} A_{s t r}}{f_{c u} b_{w}}
$$

Usually the value of $l_{a}$ is taken as twice the clear cover plus the maximum diameter of the rebar multiplied by the number of reinforcement layers. In the model proposed by [9], the stress distribution factor, $k$ has been attributed to the linear variation of resultant stress across the depth by considering force and moment equilibrium which states shear strength as,

$$
V_{\text {tan }}=\frac{1}{\frac{4 \sin \theta_{S} \cos \theta_{S}}{A_{c} f_{t}}+\frac{\sin \theta_{S}}{A_{s t r} f_{c}^{\prime}}}
$$

Where, $A_{c}$ is the beam effective cross sectional area of concrete, $f_{t}$ is the concrete tensile strength and $f_{c}$ is the concrete compressive strength. Here the principal tensile stress is calculated by considering the effective area of concrete resisting tension which has been derived by satisfying compatibility condition at the verge of impending crack formation in concrete as shown in Fig.2. The discrepancies involved in applying the stress distribution factor, $k$ based on the assumption of rectangular or linear stress distribution has been attributed to the assumption itself where such factor has been introduced comprehending loosely to suit the experimental data rather than being rational in its accord. By conceiving the proposed model the desired rationality is achieved by means of satisfying compatible condition which meets the requirements of the lower bound solution of plastic theory. The principal tensile stress, $f_{1}$ at the CompressionCompression-Tension zone (CCT node) at the top of pier cap is given by,

$$
f_{1}=\frac{T \sin \theta_{S}}{A_{c e} / \sin \theta_{s}}
$$

Where, $A_{c e}=$ Effective cross sectional area resisting tension. The term $A_{c e}$ is defined as,

$$
A_{c e}=b_{w} d_{e t}
$$

Here $d_{e t}$ is the effective depth of concrete resisting tension which is derived by satisfying the compatibility equation at the time of impending crack formation in concrete. By taking maximum compressive strain in concrete as 0.002 and tensile strain in the tie as $f_{y} / E_{s}+0.002$ (offsetting $0.2 \%$ for proof stress), we get the effective depth of the section of concrete that takes part in resisting tension by considering linear strain distribution function as,

$$
d_{e t}=\frac{d_{e}\left[0.002+f_{y} / E_{s}\right]}{0.004+f_{y} / E_{s}}
$$

Where, $d_{e}$ is effective depth of the cross section, $f_{y}$ is the yield stress of the main tie steel and $E_{s}$ is the modulus of elasticity of the steel. From the Eq. (9), the concrete area resisting tension is dependent only on the grade of main tie steel that is the condition of stress at the lower limit of 
failure, which satisfies compatibility condition for the assumed strain distribution. The maximum combined tensile strength of concrete and steel is given by,

$$
f_{t}=f_{s t}+f_{c t}
$$

Here $f_{s t}$ is the strength contributed by main steel; which is given by,

$$
f_{s t}=\frac{A_{s} f_{y} \sin \theta_{s}}{A_{c e} / \sin \theta_{s}}
$$

Since no universally accepted formula for finding tensile strength of cracked concrete exist, one argues upon their empirical basis in deriving for its suitability in predicting the concrete behavior accurately apart from the fact that concrete cracks in number of planes at various degrees.

Tensile strength of cracked reinforced concrete at the ultimate state proposed by [11] is considered here for its tension stiffening effect consideration in deriving the equation, which is given by,

$$
f_{c t}=0.31 \sqrt{f_{c}}\left(\frac{\varepsilon_{c r}}{\varepsilon_{1}}\right)^{0.4}
$$

Where, $f_{c}$ is the concrete compressive strength in MPa; $\varepsilon_{c r}$ is the strain of concrete at cracking taken as 0.0008; $\varepsilon_{1}$ is the principal tensile strain in concrete which is calculated from,

$$
\varepsilon_{1}=\varepsilon_{s}+\left(\varepsilon_{s}+\varepsilon_{2}\right) \cot ^{2} \theta_{s}
$$

Where, $\varepsilon_{s}$ is the tensile strain of longitudinal steel; $\varepsilon_{2}$ is the peak compressive strain of concrete strut, usually taken as 0.002 .

Since the concrete in the top nodal zone is under biaxial Compression-Tension state, the compressive strength of concrete is significantly reduced by concrete softening effect produced by transverse tensile stress. So the failure criterion by taking into consideration the concrete softening effect proposed by [12] under biaxial tension-compression state is applied here as,

$$
\frac{f_{1}}{f_{t}}+0.8 \frac{f_{2}}{f_{c}}=1
$$

By using Eqs. (1) and (2) on (3) and (7) and substituting them in (14) along with Eq. (10), we get the proposed nominal shear strength of the structure as,

$$
V_{n}=\frac{1}{\frac{\sin \theta_{S}}{2 f_{t} A_{c e}}+\frac{0.8 \sin \theta_{S}}{A_{s t r} f_{c}}}
$$

Here, $l_{c}=\frac{V_{n}}{f_{c} b_{w} \tan \theta_{s}}$ is the height of the bottom CCC nodal zone. However we can safely assume $l_{c}=l_{a}$ the outcome is insignificantly altered.

\section{Validation of Proposed Model}

The Strut-and-Tie model proposed here is validated with 43 test results by author and from the previous studies. There exist insufficient experimental data available on reinforced concrete bridge pier cap, hence the test results of midpoint load on deep beams has been considered here for validating our proposed STM model. The experiment results $\left(V_{\text {exp }}\right)$ and predicted values $\left(V_{\text {pred }}\right)$ have been compared and variations have been tabulated in the Table.1.The concrete compressive strength of the experiment models varied from 23.2 to105 $\mathrm{MPa}$, including normal strength concrete and high strength concrete. The shear span to depth ratio ranges from 0.3 to 2.02 having depth ranging from $350 \mathrm{~mm}$ to $1100 \mathrm{~mm}$. The longitudinal reinforcement varies from $.03 \%$ to $2 \%$. The accuracy of the proposed model is related with $a / d$ ratio and it is inferred from the results $V_{\text {exp }} / V_{\text {pred }}$ that the proposed model can be applied to the shear span ranging from 0.5 to 1.75 without significant loss of accuracy of about $14 \%$ of experimental results. It has to be noted 
that the entire range of tested models have failed in Biaxial Compression-Tension state for which the devised ultimate shear strength $V_{n}$ formula is used.

Table 1

Predictions and Comparisons

\begin{tabular}{|c|c|c|c|c|c|c|c|c|}
\hline S.No & Reference & $a / d$ & $f_{c}\left(\mathrm{~N} / \mathrm{mm}^{2}\right)$ & $f_{y}\left(\mathrm{~N} / \mathrm{mm}^{2}\right)$ & $V_{\exp }(K N)$ & $V_{\text {pred }}(K N)$ & $V_{\tan }(K N)$ & $\frac{V_{\text {exp }}}{V_{\text {pred }}}$ \\
\hline 1 & A1 & 0.5 & 23.2 & 415 & 48 & 43 & 39 & 1.11 \\
\hline 2 & A2 & 0.7 & 23.2 & 415 & 78 & 84 & 64 & 0.93 \\
\hline 3 & A3 & 1.05 & 23.2 & 415 & 112 & 125 & 96 & 0.90 \\
\hline 4 & A4 & 1.2 & 23.2 & 415 & 160 & 148 & 135 & 1.08 \\
\hline 5 & A5 & 1.4 & 23.2 & 415 & 190 & 168 & 157 & 1.13 \\
\hline 6 & P1 & 0.54 & 46.1 & 445 & 946 & 745 & 690 & 1.27 \\
\hline 7 & P2 & 0.75 & 46.1 & 445 & 697 & 610 & 570 & 1.14 \\
\hline 8 & P3 & 1.23 & 46.1 & 445 & 355 & 470 & 431 & 0.76 \\
\hline 9 & CAPN & 2.02 & 35 & 468.5 & 2920 & 2200 & 2037 & 1.33 \\
\hline 10 & CAPH & 2.02 & 70 & 468.5 & 3000 & 2535 & 2369 & 1.18 \\
\hline 11 & $\mathrm{~B} 1 / 1.0$ & 0.75 & 26.1 & 400 & 699 & 561 & 515 & 1.25 \\
\hline 12 & B2/1.0 & 0.75 & 26.8 & 400 & 750 & 570 & 528 & 1.32 \\
\hline 13 & DC & 0.48 & 40.4 & 444 & 502 & 420 & 393 & 1.20 \\
\hline 14 & DB1 & 1.7 & 42.4 & 455 & 606 & 557 & 511 & 1.09 \\
\hline 15 & DB2 & 0.25 & 30.2 & 428 & 586 & 425 & 394 & 1.38 \\
\hline 16 & B1 & 0.34 & 87 & 400 & 1200 & 1120 & 1047 & 1.07 \\
\hline 17 & B2 & 0.34 & 87 & 400 & 1300 & 1156 & 1061 & 1.12 \\
\hline 18 & B3 & 0.34 & 92 & 400 & 860 & 750 & 694 & 1.15 \\
\hline 19 & B4 & 0.34 & 92 & 400 & 1500 & 1252 & 1170 & 1.20 \\
\hline 20 & B5 & 0.34 & 56 & 400 & 100 & 90 & 83 & 1.11 \\
\hline 21 & B6 & 0.34 & 56 & 400 & 1200 & 1025 & 949 & 1.17 \\
\hline 22 & B7 & 0.5 & 90 & 400 & 950 & 850 & 794 & 1.12 \\
\hline 23 & B8 & 0.5 & 90 & 400 & 700 & 620 & 569 & 1.13 \\
\hline 24 & B9 & 0.55 & 90 & 400 & 470 & 410 & 380 & 1.15 \\
\hline 25 & B10 & 0.5 & 62 & 400 & 980 & 900 & 841 & 1.09 \\
\hline 26 & B11 & 0.5 & 62 & 400 & 700 & 625 & 573 & 1.12 \\
\hline 27 & B12 & 0.5 & 62 & 400 & 580 & 496 & 459 & 1.17 \\
\hline 28 & B13 & 0.5 & 62 & 400 & 490 & 412 & 385 & 1.19 \\
\hline 29 & B14 & 0.5 & 95 & 400 & 1000 & 925 & 849 & 1.08 \\
\hline 30 & B15 & 0.5 & 65 & 400 & 1000 & 915 & 847 & 1.09 \\
\hline 31 & B16 & 0.6 & 53 & 400 & 550 & 485 & 453 & 1.13 \\
\hline 32 & B17 & 0.6 & 53 & 400 & 800 & 725 & 665 & 1.10 \\
\hline 33 & B18 & 0.6 & 105 & 400 & 1180 & 1050 & 972 & 1.12 \\
\hline 34 & B19 & 0.6 & 105 & 400 & 1150 & 1025 & 958 & 1.12 \\
\hline 35 & B20 & 033 & 53 & 400 & 650 & 595 & 546 & 1.09 \\
\hline 36 & B21 & 0.3 & 53 & 400 & 1040 & 980 & 907 & 1.06 \\
\hline 37 & B22 & 0.4 & 71 & 400 & 960 & 860 & 804 & 1.12 \\
\hline 38 & B23 & 1.0 & 71 & 400 & 680 & 585 & 537 & 1.16 \\
\hline 39 & B24 & 1.0 & 71 & 400 & 710 & 650 & 602 & 1.09 \\
\hline 40 & B25 & 0.3 & 105 & 400 & 750 & 670 & 626 & 1.12 \\
\hline 41 & B26 & 0.3 & 105 & 400 & 1050 & 980 & 899 & 1.07 \\
\hline 42 & B27 & 0.6 & 45 & 400 & 674 & 580 & 537 & 1.16 \\
\hline 43 & B28 & 0.6 & 94 & 400 & 1050 & 985 & 921 & 1.07 \\
\hline & & & & & & & AVG(C.O.V & 1.14 \\
\hline
\end{tabular}

Ref-SNo: 1-5 Author,6-8 [13],9-10[14],11-12 [15],13 [16],14 [17],15 [18],16-43 [19] 
The proposed STM proves to be 86\% efficient in predicting the ultimate shear strength of pier cap. The average coefficient of variation between the experimental shear strength and predicted shear strength is 1.14 as can be found in the Fig 3.

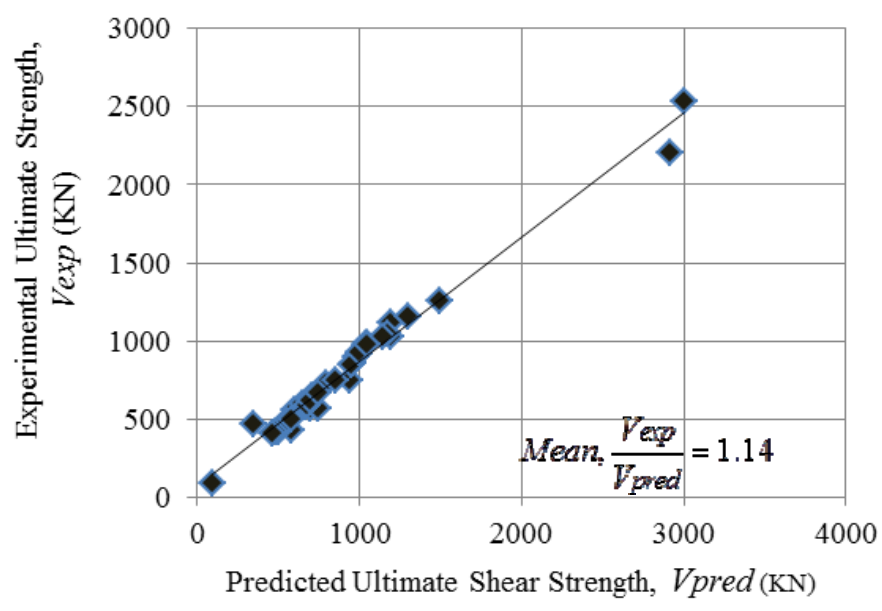

Fig.3 - Shear Strength Prediction and Comparison

\section{Parametric study}

To understand the sensitivity of the ultimate shear strength to various material properties and dimensional parameters such as shear span to depth ratio, bearing width, struts and nodal dimensions, a detailed parametric study is carried out. The shear span to depth ratio being the defining attribute of the structure influences the shear carrying capacity of the pier cap to a greater extent than any material parameters or strain assumptions.

\subsection{Sensitivity of Shear Strength to Span to Depth Ratio}

The shear span to depth ratio $(a / d)$ is the major dimensional factor upon which the shear strength of the structure depends entirely. Other factors such as length of bearing plate, depth of the nodal zone or width of the pier cap have less than 3\% effect on the ultimate shear strength. As given in Fig.4, influence of shear span to depth ratio on shear strength is more of a convex parabolic nature attaining convergence from the $a / d$ ratio 1.75 and less sensitive thereafter. For constant shear span ' $a$ ', more the depth more rapidly the resistance to shear increases until the $a / d$ ratio of 1.75 and so it can be said that value between 1.75 and 2.0 can be taken as the optimum range of shear span to depth ratio for design of reinforced concrete pier cap

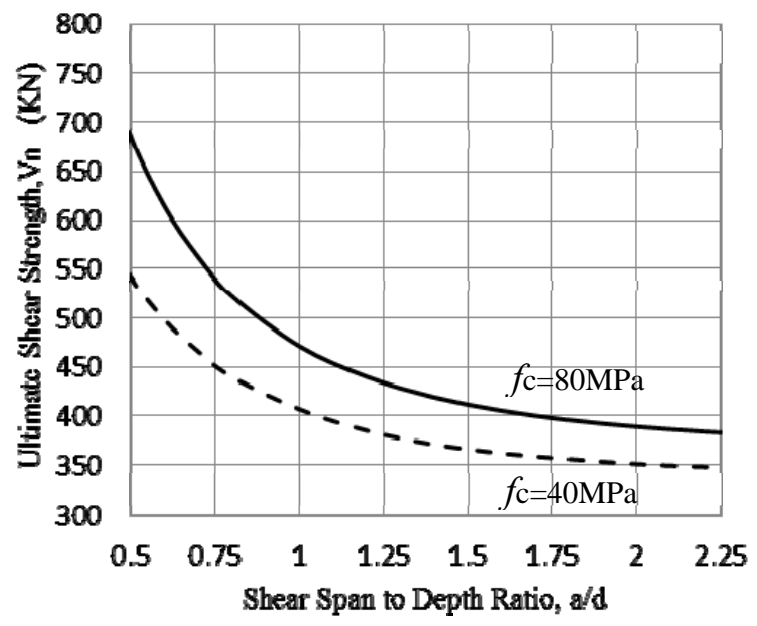

Fig.4 - Influence of a/d ratio on Shear Strength 


\subsection{Sensitivity of Shear Strength to Stress and Strain in Concrete}

The principal stresses at the nodal zone has been found out by satisfying compatibility condition at the state of impending failure. The sensitivity of shear strength with respect to the assumed compressive strain distribution is graphed out in the Fig.5 for various grades of concrete. The maximum variation is $20 \mathrm{KN}$ or $5 \%$ of the ultimate shear strength for the strain values between 0.001 and 0.004 . Shear strength varies as a linear function of maximum compressive strain.

Also for high strength concrete ( $>60 \mathrm{MPa}$ ) the slope of shear strength of the pier cap with respect to compressive strength of concrete is steeper than that of low strength concrete which can be attributed to higher value of young's modulus for high strength concrete resulting in extended stress-strain relation. For higher value of strain in compression zone concrete, less will be the effective depth of concrete resisting tension and eventually less shear strength. By such basis of strain compatibility, we eliminate the unnecessary complications involved in high nonlinearity of tensile stress distribution.

The variation of shear strength with compressive strength of concrete behaves as a concave parabolic function as given in Fig.6 for maximum compressive strain of 0.002. The ultimate shear strength decreases by $22 \%$ for every $50 \%$ increase in a/d ratio whereas it increases only $2.7 \%$ for every $50 \%$ increase in concrete compressive strength. Thus shear span to depth ratio plays significant role when compared to compressive strength of concrete.

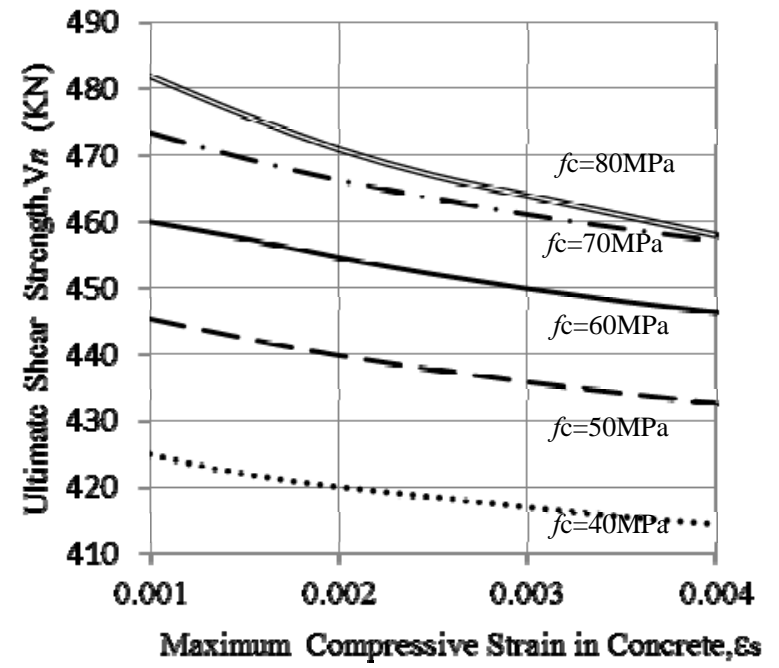

Fig.5 - Shear Strength as a function of Maximum Compressive Strain in Concrete

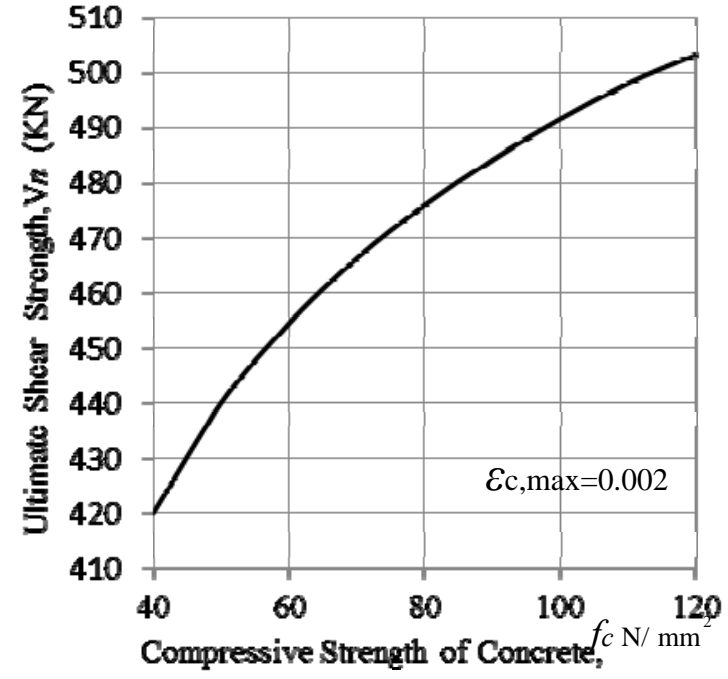

Fig.6 - Shear Strength as a function of Compressive Strength in Concrete

\section{Conclusion}

The proposed STM having accuracy of $86 \%$ in predicting the ultimate shear strength of the structure can be conservatively used to determine the ultimate shear strength of Pier cap having the shear span to depth ratio of 0.4 to 2.4 and for a wide range of concrete grades. The main advantage of using the proposed model lies in discarding the stress distribution factor and replacing with strain compatible effective depth of concrete resisting tension which has very less influence of mere $5 \%$ of mean strength over the ultimate shear strength as compared to 15 to $20 \%$ variation produced by stress distribution factor $k$ derived by satisfying both force and moment equilibrium condition which fails to rationalize on which $k$ values has to be used. So the ultimate shear strength is insensitive to the strain value being assumed in deriving the shear 
capacity formula. Any respective codal maximum concrete compressive strain value can be assumed without affecting the ultimate shear strength value significantly. Also it has been observed that the optimum range of $a / d$ ratio is 1.75 to 2.0 for which the tradeoff exists between shear strength and the volume of material. This paper tries to extend the practical application of Strut-and-Tie Model for reinforced concrete bridge pier cap in understanding the actual behavior of the structure on various dimensional and material parameters.

\section{References}

[1] Schlaich, J., Schäfer, K. and Jennewein, M. (2008). Toward a Consistent Design of Structural Concrete. PCI Journal, 82(1), 74-150.

[2] Karl-Heinz-Reineck. (2002). Example for Design of Structural Concrete with Strut-and-Tie Model. ACI-SP-208.

[3] ACI Committee 318. (2008). Building Code Requirements for Structural Concrete ( ACI 318-08). American Concrete Institute (Vol. 2007). http://doi.org/10.1016/0262-5075(85)90032-6.

[4] Alshegeir, A. and Ramirez, J. (1992). Computer Graphics in Detailing Strut-Tie Models. Journal of Computing in Civil Engineering, 6(2), 220-232. http://doi.org/10.1061/(ASCE)0887-3801(1992)6:2(220)

[5] Marti, P. (1985). Basic tools of reinforced concrete beam design. ACI, 82(1), 46-56.

[6] Alshegeir, A. (1992). Analysis and design of disturbed regions with strut-tie models. Ph.D. thesis, West Lafayette (IN), Purdue University.

[7] MacGregor, J. G. (1988). Reinforced concrete: Mechanics and design. Prentice Hall, 848.

[8] Foster, S. J. and Malik, A. R. (2002). Evaluation of Efficiency Factor Models used in Strut-and-Tie Modeling of Nonflexural Members. Journal of Structural Engineering, 128(5), 569. http://doi.org/10.1061/(ASCE)07339445(2002)128:5(569)

[9] Zhang, N. and Tan, K. H. (2007). Direct strut-and-tie model for single span and continuous deep beams. Engineering Structures, 29(11), 2987-3001. http://doi.org/10.1016/j.engstruct.2007.02.004

[10] Wang, G. L. and Meng, S. P. (2008). Modified strut-and-tie model for prestressed concrete deep beams. Engineering Structures, 30(12), 3489-3496. http://doi.org/10.1016/j.engstruct.2008.05.020

[11] Belarbi,.A., Hsu, T. T. C. (1994). Constitutive laws of concrete in tension and reinforcing bar stiffened by concrete. ACI Struct J, 91(4)(1994), 465-74.

[12]Cedolin, L. and Mulas, M. G. (1984). Biaxial Stress-Strain Relation for Concrete. Journal of Engineering Mechanics, 110(2), 187-206. http://doi.org/10.1061/(ASCE)0733-9399(1984)110:2(187)

[13] Sami. (1990). The Response of Reinforced Concrete.

[14] McLeod, G. (1997). Influence of Concrete Strength on the Behaviour of Bridge Pier Caps. McGill University, Montreal, Canada.

[15] Rogowsky, D.M., MacGregor, J.G. and Ong, S. Y. (1983). Tests of reinforced concrete deep beams. Univ. of Alberta, Canada.

[16] Cook, W.D. and Mitchell, D. (1988). Studies of disturbed regions near discontinuities in Reinforced Concrete Members. ACI Struct J, 85(2), 206-216.

[17] Rogowsky, D. M. and MacGregor, J. G. (1983). Tests of Reinforced Concrete Deep Beams.pdf.

[18] Leonhardt, F. and Walther, R. (1966). WandartigerTraiger. DeutscherAusschuss Fur Stahlebeton, Wilhelm Er, Bulletin No.178,Berlin 159.

[19] Gilbert., S. J. F. and R. lan. (1998). Experimental studies on high-strength concrete deep beams. ACI Structural Journal, 95(4)(1998), 382-390. 